\title{
Three synonymous genes encode calmodulin in a reptile, the Japanese tortoise, Clemmys japonica
}

\author{
Kouji Shimoda, Toshihiro Miyake, Jun Kimura, Kazuyoshi Maejima \\ Laboratory Animal Center, Keio University School of Medicine, Tokyo, Japan
}

\begin{abstract}
Three distinct calmodulin (CaM)-encoding cDNAs were isolated from a reptile, the Japanese tortoise (Clemmys japonica), based on degenerative primer PCR. Because of synonymous codon usages, the deduced amino acid (aa) sequences were exactly the same in all three genes and identical to the aa sequence of vertebrate $\mathrm{CaM}$. The three CDNAs, referred to as CaM-A, $-B$, and $-C$, seemed to belong to the same type as CaMI, CaMII, and CaMIII, respectively, based on their sequence identity with those of the mammalian cDNAs and the glutamate codon biases. Northern blot analysis detected $C a M-A$ and $-B$ as bands corresponding to $1.8 \mathrm{~kb}$, with the most abundant levels in the brain and testis, while CaM-C was detected most abundantly in the brain as bands of 1.4 and $2.0 \mathrm{~kb}$. Our results indicate that, in the tortoise, CaM protein is encoded by at least three non-allelic genes, and that the 'multigene-one protein' principle of CaM synthesis is applicable to all classes of vertebrates, from fishes to mammals.
\end{abstract}

Key words: reptile, cDNA, synonymousgenes.

Received: March 14, 2002; accepted: March 25, 2002.

\section{Introduction}

Calmodulin (CaM), a prototype of EF-hand $\mathrm{Ca}^{2+}$-binding protein, is ubiquitously distributed in all eukaryotic cells, and is particularly abundant in the brain and testes of mammals (Kakiuchi et al., 1982). CaM function is essential for the viability of cells and tissues, as well as for neuronal activity in the central nervous system (CNS) (Kennedy, 1989). When $\mathrm{CaM}$ binds to the $\mathrm{Ca}^{2+}$ ion, the protein becomes active, and it in turn activates many other enzymes. It thus plays a pivotal role as a cofactor regulating a wide variety of calcium-dependent proteins.

The amino acid (aa) sequence of CaM protein is well conserved in organisms whose evolution diverged millions of years ago. Three non-allelic $\mathrm{CaM}$ genes encoding exactly the same 148 aa protein (17,000 daltons) were identified in the rat (Nojima, 1989 ), mouse (Bender et al., 1988; Danchin et al., 1989), and humans (Fischer et al., 1988); two were identified in Xenopus (Chien and Daxid, 1984), and four in the teleost fish medaka (Oryzias latipes) (Matsuo et al., 1992). Although the reason for the presence of multiple synonymous genes in animals is unclear, differences in the 5' and 3' non-coding region of the rat $\mathrm{CaM}$ genes suggest that each gene may be differentially

Send correspondence to Kouji Shimoda, Laboratory Animal Center, Keio University School of Medicine, 35-Shinanomachi, Shinjuku-ku, 160-8582, Tokyo, Japan. E-mail: shimodak@sc.itc. keio.ac.jp. regulated. The overall distribution of the three $\mathrm{CaM}$ transcripts was coordinated in rat brain (Ikeshima et al., 1993; Palfi et al., 1999 ), however, temporal and spatial differences in the expression of $\mathrm{CaM}$ genes have been observed in some areas of the CNS, both under physiological and experimental conditions (Michelhaugh et al., 1998; Palfi and Gulya, 1999; Palfi et al., 2000, Palfi et al., 2001, Shimizu et al., 1997; Sola et al., 1997; Weinman et al., 1991). Knowledge of the evolutionary relationships between vertebrate $\mathrm{CaM}$ genes should provide useful information (in) regarding (to) this multiple-gene system. To this study, we attempted to isolate $\mathrm{CaM}$ cDNAs from a reptile, the Japanese tortoise (Clemmys japonica), which occupies a critical position in the phylogenetic tree of vertebrate evolution. The results indicate that reptiles also possess three active $\mathrm{CaM}$ genes, corresponding to CaMI, CaMII, and CaMIII, respectively, and thus the 'multigene-one protein' principle of $\mathrm{CaM}$ synthesis is as applicable to reptiles as it is to other vertebrates.

\section{Materials and Methods}

\section{Isolation of total RNA}

The Japanese tortoise was purchased from a commercial source. The animal was anesthetized by ethyl-ether and euthanized by decapitation on ice. Dissected organs (brain, liver, kidneys, intestines, heart, and testes) were immediately frozen in liquid nitrogen. Total organ RNA 
preparations were obtained by the guanidine-thiocyanate-CsCl ultra-centrifugation method (Chirgwin et al., 1979).

\section{Amplification, subcloning and sequencing of $\mathrm{CaM}$ cDNA}

A set of degenerate primers was synthesized by a DNA synthesizer, as described in a previous paper (Matsuo et al., 1992): Amino-terminal: 5'-ATG GCN GAY CAR CTN ATN GA and Carboxyl-terminal: 5'-GGGTCTAGA YA YTT NGC NGT CAT CAT YTG. N represents an A, $\mathrm{G}, \mathrm{C}$, or T base; $\mathrm{Y}$, a C or T base; and R, an A or G base. The underlined bases indicate an $X b a \mathrm{I}$ site. First-strand cDNA was synthesized from $2 \mu \mathrm{g}$ of total RNA using 50 pmol of the Carboxyl-terminal degenerate primer as described by Kawasaki (1990). RCR was performed according to the methods described in a previous paper (Matsuo et al., 1992). PCR products were treated with Klenow (large) fragment of E. coli DNA polymerase I, digested with XbaI, and fractionated in $1.5 \%$ agarose gel. About 450 -bp bands were cloned between the Sma I and Xba I sites of pUC19. Nucleotide sequence analysis was performed by a DNA sequencer (373A, Applied Biosystems, CA) with Cycle Sequencing Kit (Takara, Tokyo), according to the manufacturer's instructions. Each nucleotide sequence was confirmed from both directions. The sequences of these cDNAs appeared in the DDBJ/EMBL/GenBank under accession Nos. AB055384 (CaM-A), AB055385 (CaM-B) and AB055386 (CaM-C).

\section{Southern blot hybridization}

One hundred ng of cloned CaM genes, $\mathrm{CaM}-\mathrm{A},-\mathrm{B}$ and -C, were digested with $\mathrm{XbaI}$ and EcoRI restriction enzymes, submitted to electrophoresis in $0.8 \%$ agarose gel, and then blotted onto a NYTRAN membrane (Schleicher \& Schuell). The membrane was pre-hybridized at $65^{\circ} \mathrm{C}$ in hybridization solution (6 x SSC/50 mM sodium phosphate buffer, $\mathrm{pH} 7.0 / 2$ $x$ Denhardt's solution $/ 0.5 \%$ SDS $/ 0.2 \mathrm{mg}$ salmon sperm DNA $/ \mathrm{mL}$ ). A random hexamer-primed ${ }^{32}$ P-labeled DNA probe of each coding region was added and allowed to hybridize for $20 \mathrm{~h}$ at $65^{\circ} \mathrm{C}$. The membrane was washed twice in $2 \times \mathrm{SSC} / 0.1 \% \mathrm{SDS}$ at room temperature for $5 \mathrm{~min}$, twice in $0.1 \times \mathrm{SSC} / 0.1 \% \mathrm{SDS}$ at $65^{\circ} \mathrm{C}$ for $20 \mathrm{~min}$, and exposed to $\mathrm{X}$-ray film overnight at $-80^{\circ} \mathrm{C}$.

\section{Northern blot analysis}

Five $\mu \mathrm{g}$ of total tortoise RNA were denatured with glyoxal and dimethyl sulfoxide, submitted to electrophoresis in $1.0 \%$ agarose gel, and then blotted onto a NYTRAN membrane. The membrane was pre-hybridized for $4 \mathrm{~h}$ at $68{ }^{\circ} \mathrm{C}$ in hybridization solution $(50 \%$ formamide $/ 5 \mathrm{x}$ $\mathrm{SSC} / 50 \mathrm{mM}$ sodium phosphate buffer, $\mathrm{pH} 7.0 / 2 \mathrm{x}$ Denhardt's solution $/ 0.5 \% \mathrm{SDS} / 0.2 \mathrm{mg}$ salmon sperm $\mathrm{DNA} / \mathrm{mL}$ ). A random hexamer-primed ${ }^{32} \mathrm{P}$-labeled DNA probe of each coding region was added and allowed to hybridize for $20 \mathrm{~h}$ at $68{ }^{\circ} \mathrm{C}$. The membrane was washed three times in $0.2 \times \mathrm{SSC} / 0.1 \% \mathrm{SDS}$ at $68^{\circ} \mathrm{C}$ for $20 \mathrm{~min}$, and exposed to X-ray film overnight at $-80^{\circ} \mathrm{C}$.

\section{Results}

\section{Isolation of three CaM-coding regions}

Our previous study showed that the degenerate primers encoding the Amino- and Carboxyl-terminal six aa of $\mathrm{CaM}$ are useful for reverse transcription and PCR of total teleost fish RNA (Matsuo et al., 1992). In this study, we also employed the same pair of degenerate primers to isolate $\mathrm{CaM}$ cDNA from transcripts of tortoise brain (Figure 1). Eleven of the $60 \mathrm{cDNA}$ clones obtained fell into three groups of distinctive CaM sequences, designated $A, B$, and $C$. The nucleotide sequences of these three groups of cDNA are shown in Figure 1. The deduced aa sequences were

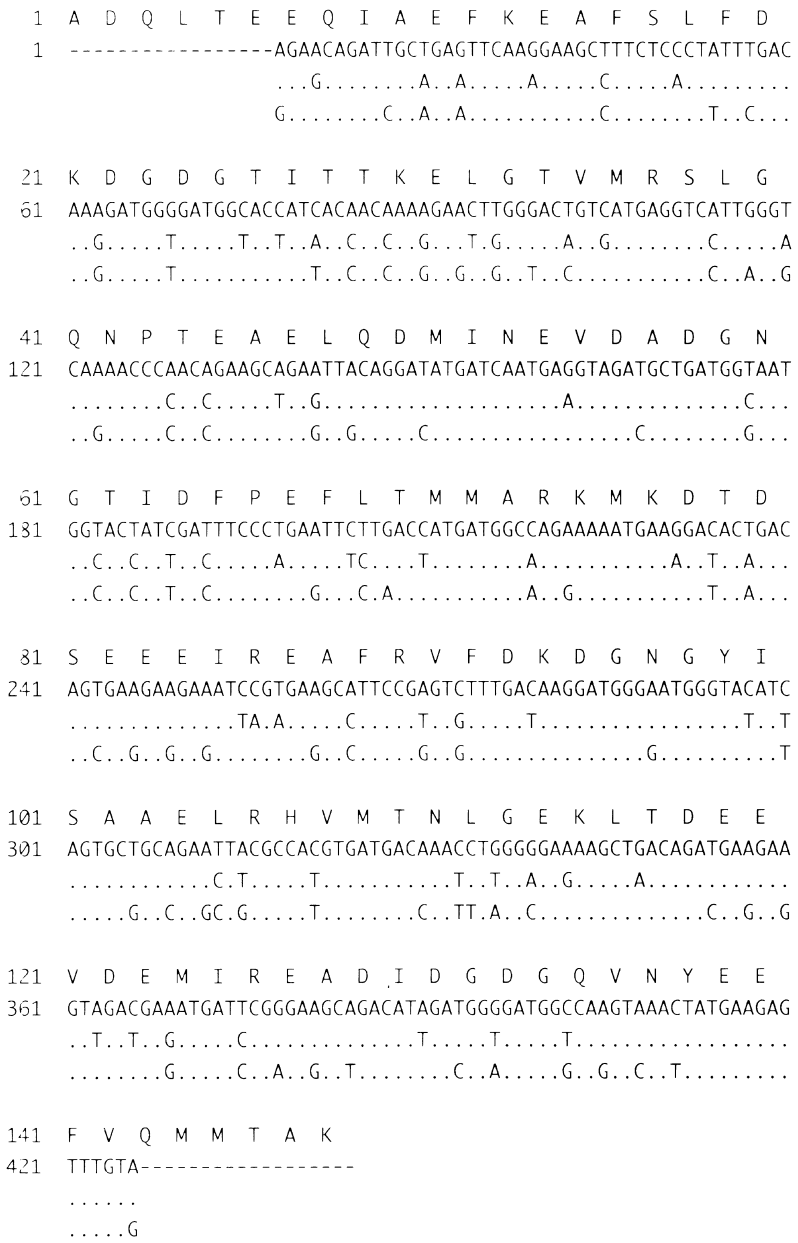

Figure 1 - The coding sequences of tortoise $\mathrm{CaM} c \mathrm{cNA}$ and their deduced aa sequence. The deduced common aa sequence is shown in the first line, and the coding sequences of the cDNA of the three tortoise CaMs, $\mathrm{CaM}-A$, $-B$, and $-C$, are shown in the second, third, and fourth line, respectively. Dashes indicate nucleotide corresponding to the primers. Dots indicate the nucleotide identical to those of $C a M-A$. The sequence of these cDNAs will appear in the DDBJ/EMBL/GenBank under accession Nos. AB055384 $(C a M-A), \mathrm{AB} 055385(C a M-B)$ and AB055386 (CaM-C). 
exactly the same, and they were identical to those of the vertebrate $\mathrm{CaM}$ genes. Since the nucleotide substitutions were scattered throughout the coding regions, the isolated coding regions were unlikely to have been generated by alternative splicing from a single gene. We therefore concluded that at least three distinct $C a M$ genes, $C a M-A,-B$, and $-C$, were transcribed in the tortoise. The existence of three different $C a M$ genes was further confirmed by Southern blot hybridization (Figure 2). Each probe of $C a M-A,-B$, and $-C$ could detect its own clone, but not others, in stringent conditions $\left(\mathrm{Tm}-7^{\circ} \mathrm{C}\right)$.

\section{Comparative analysis of the tortoise CaM sequences and codon bias of glutamate}

The sequence homologies between any two of the three tortoise cDNAs were $82 \%$ to $85 \%$, which is very low considering that they encode $\mathrm{CaM}$, i.e., a gene product with identical aa sequences. Comparisons with the $\mathrm{CaM}$ sequences of other animals showed that $C a M-A,-B$, and $-C$ exhibited the highest homology to CaMI, CaMII, and CaMIII, respectively, within each species (Table I). We therefore concluded that $C a M-A,-B$, and $-C$ should be classified as CaMI, CaMII, and CaMIII genes, respectively. This conclusion was also supported by the fact that the codon usage of glutamate, which accounts for 21 residues of the CaM protein, was biased to the GAA codon in $\mathrm{CaMI}$ and CaMII, as opposed to the GAG codon in CaMIII (Table I). However, further confirmation of sequence homology in the non-coding and regulatory regions will be necessary.

\section{Northern blot analysis}

Brain, liver, kidney, intestine, heart, and testis were analyzed for expression of tortoise $C a M$ genes by Northern blot hybridization (Figure 3 ). The $C a M-A$ and $-B$ probes detected bands of about $1.8 \mathrm{~kb}$, respectively. The strongest expression of both genes was observed in the brain and testis. The possibility remained that the $1.8 \mathrm{~kb}$ band was at least partially the result of cross-hybridization between $\mathrm{CaM}-\mathrm{A}$ and $-B$, however, the $C a M-A$ and $-B$ genes were specifically detected by Southern blot hybridization, and the expression pattern in various tissues was slightly different. The $\mathrm{CaM}-\mathrm{C}$ probe detected two bands of about 1.4 and $2.0 \mathrm{~kb}$, most prominently in the brain. The results of other studies indicated that utilization of multiple polyadenylation sites yielded CaM RNAs of different sizes in other organisms (Lagace et al., 1983; Nojima, 1989; Nojima et al., 1987).

Table I - Homology of tortoise CaM genes with mammalian genes and their glutamate codon usage.

\begin{tabular}{|c|c|c|c|c|c|}
\hline & \multicolumn{3}{|c|}{ Tortoise $^{(\mathrm{a})}$} & \multicolumn{2}{|c|}{ Glutamates $^{(\mathrm{c})}$} \\
\hline & CaM-A & CaM-B & CaM-C & GAA & GAG \\
\hline \multicolumn{6}{|l|}{ Human } \\
\hline CaMI & $88.0^{*(b)}$ & 84.6 & 80.4 & 20 & 1 \\
\hline CaMII & 84.6 & $92.4 *$ & 79.2 & 17 & 4 \\
\hline CaMIII & 82.4 & 83.4 & $85.1^{*}$ & 2 & 19 \\
\hline \multicolumn{6}{|l|}{ Rat } \\
\hline CaMI & $87.5^{*}$ & 81.7 & 81.2 & 14 & 7 \\
\hline CaMII & 83.9 & $88.5^{*}$ & 80.2 & 16 & 5 \\
\hline CaMIII & 83.4 & 83.6 & 86.1 & 6 & 15 \\
\hline \multicolumn{6}{|l|}{ Mouse } \\
\hline CaMI & $84.4^{*}$ & 83.4 & 82.2 & 15 & 6 \\
\hline CaMII & 83.9 & $89.7 *$ & 81.2 & 12 & 9 \\
\hline CaMIII & 82.2 & 84.3 & $86.8^{*}$ & 4 & 17 \\
\hline \multicolumn{6}{|l|}{ Tortoise } \\
\hline CaM-A & - & 84.8 & 81.7 & 17 & 4 \\
\hline CaM-B & - & - & 83.1 & 16 & 5 \\
\hline CaM-C & - & - & - & 4 & 17 \\
\hline
\end{tabular}

a) The pairwise sequence alignment was performed in the 409 nucleotide indicated in Figure 1.

b) Sequence identities (\%) with corresponding mammalian genes are shown. Asterisks (*) indicate the highest homology with CaM genes in the species.

c) CaM protein contains 21 glutamate residues.

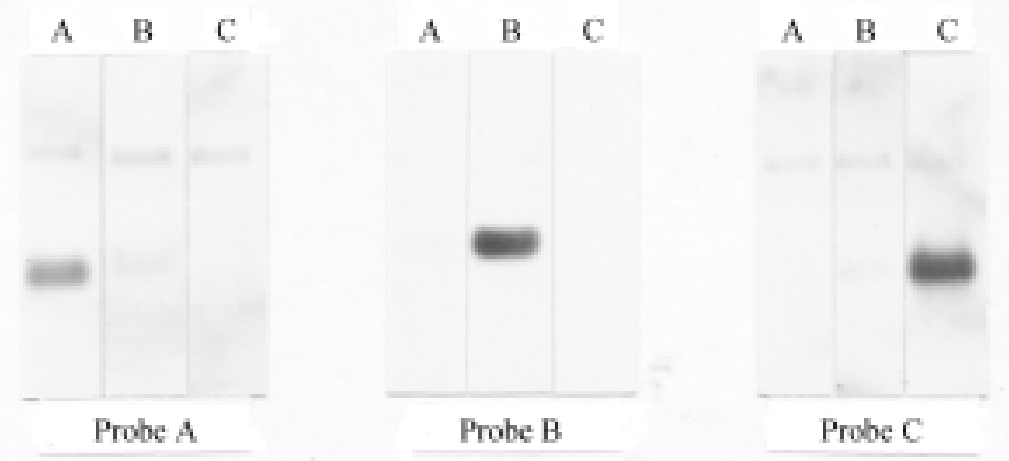

Figure 2 - Southern blot analysis of tortoise cDNAs. Tortoise cDNAs of $C a M-A,-B$, and $-C$ were digested with $X b a \mathrm{I}$ and $E c o R$ I restriction enzymes, and three sets of digested DNAs underwent electrophoresis and were then blotted onto membrane. Lanes A, B and C indicate cDNAs of $C a M-A$, $-B$ and $-C$, respectively. Probes A, B, and C indicate a random hexamer-primed ${ }^{32} \mathrm{P}$-labeled DNA probe of, respectively, the $C a M-A,-B$, and $-C$ coding regions. Each $C a M-A,-B$, and $-C$ probe could detect its own clone, but not others. Faint signals were visible in the position of vector plasmid pUC19 in probes A and C, and slight cross-hybridizations between $C a M-B$ and probes $\mathrm{A}$ and $\mathrm{C}$ were also detectable. 


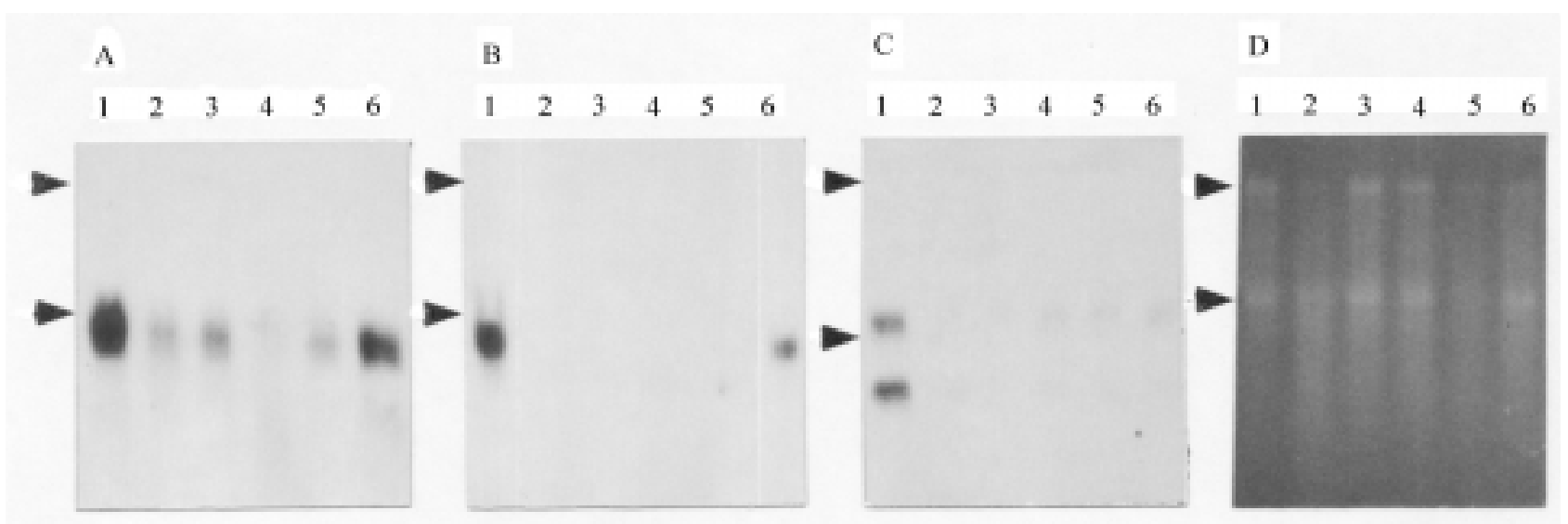

Figure 3 - Northern blot analysis of tortoise RNA in various tissues. Tortoise $C a M-A,-B$, and $-C$ cDNAs were used as probes in panels A, B, and C, respectively, and an EtdBr-stained gel is shown in panel D. Lanes 1-6 represent total RNA isolated from brain, liver, kidney, intestine, heart, and testis, respectively. About $5 \mu \mathrm{g}$ of total RNA underwent electrophoresis in $1.0 \%$ agarose gel. Arrowheads indicate the positions of the major ribosomal RNA bands of the Japanese tortoise.

Our results clearly demonstrate that the $\mathrm{CaM}$ protein of the tortoise is encoded by at least three independent $\mathrm{CaM}$ transcripts.

\section{Discussion}

The 'multigene-one protein' principle of CaM synthesis is conserved in the reptile, and thus seems to be common to all classes of vertebrates (Toutenhoofd and Strehler, 2000). The nt sequence homologies between any two of the three types of CaM cDNA are very low, considering that the aa sequence of CaM protein is identical in all vertebrates. Comparisons with the nt sequences of other animals may provide some information concerning the type of $\mathrm{CaM}$ cDNA (Table I). Our results also indicate that the codon usage of glutamate is an additional landmark for the classification of $\mathrm{CaM}$ genes.

Although we do not know why organisms that lost the multiple $\mathrm{CaM}$ gene system failed to survive natural selection, this multigene system may confer proper expression of $\mathrm{CaM}$ protein in the cells of vertebrate tissues. While all three $\mathrm{CaM}$ genes are coordinately expressed in adult rat brain (Ikeshima et al., 1993), slight but definite differences in individual gene expression have been observed in CNS neurons under normal conditions (Palfi et al., 1999). Differential responses of $\mathrm{CaM}$ genes in the rat brain after administration of psychotropic drugs (Michelhaugh et al., 1998; Shimizu et al., 1997) and a convulsant neurotoxic agent (Sola et al., 1997) have also been reported. Our previous studies indicated that the disparate promoters of rat CaMII and CaMIII direct similar, but not identical, expression patterns in the CNS of adult and fetal transgenic mice (Matsuo et al., 1993; Shimoda et al., 1995). Further analysis of the CaM 5' and 3'-flanking regions in reptiles and other vertebrates is needed to confirm both the regulatory mechanisms and the evolutionary relationships of $\mathrm{CaM}$ genes.

\section{Acknowledgments}

We wish to express our sincere thanks to Dr. Hiroko Ikeshima for valuable suggestions. This study was partly supported by Grants-in-Aid for Scientific Research from the Ministry of Education, Science, Sports, and Culture of Japan, and Grants from the Keio University.

\section{References}

Bender PK, Dedman JR and Emerson Jr CP (1988) The abundance of calmodulin mRNAs is regulated in phosphorylase kinase-deficient skeletal muscle. J. Biol. Chem. 263:9733-9737.

Chien YH and Dawid IB (1984) Isolation and characterization of calmodulin genes from Xenopus laevis. Mol. Cell. Biol. 4:507-513.

Chirgwin JM, Przybyla AE, MacDonald RJ and Rutter WJ (1979) Isolation of biologically active ribonucleic acid from sources enriched in ribonuclease. Biochemistry 18:5294-5299.

Danchin A, Sezer O, Glaser P, Chalon P and Caput D (1989) Cloning and expression of mouse-brain calmodulin as an activator of Bordetella pertussis adenylate cyclase in Escherichia coli. Gene 80:145-149.

Fischer R, Koller M, Flura M, Mathews M, Strehler-Page MA, Krebs J, Penniston JT, Carafoli, E and Strehler, EE (1988) Multiple divergent mRNAs code for a single human calmodulin. J. Biol. Chem. 263:17055-17062.

Ikeshima H, Yuasa S, Matsuo K, Kawamura K, Hata J and Takano $\mathrm{T}$ (1993) Expression of three non-allelic genes coding calmodulin exhibits similar localization on the central nervous system of adult rats. J. Neurosci. Res. 36:111-119.

Kakiuchi S, Yasuda S, Yamazaki R, Teshima Y, Kanda K, Kakiuchi R and Sobue K (1982) Quantitative determinations of calmodulin in the supernatant and particulate fractions of mammalian tissues. J. Biochem. 92:1041-1048.

Kawasaki ES (1990) Amplification of RNA. In: Innis MA, Gelfand DH, Sninsky JJ, and White, TJ (eds) PCR Protocols. Academic Press, San Diego, pp. 21-27.

Kennedy MB (1989) Regulation of neuronal function by calcium. Trends Neurosci. 12:417-420. 
Lagace L, Chandra T, Woo SLC and Means AR (1983) Identification of multiple species of calmodulin messenger RNA using a full length complementary DNA. J. Biol. Chem. 258:1684-1688.

Matsuo K, Ikeshima H, Shimoda K, Umezawa A, Hata J, Maejima K, Nojima H and Takano T (1993) Expression of the rat calmodulin gene II in the central nervous system: a 294-base promoter and 68-base leader segment mediates neuron-specific gene expression in transgenic mice. Mol. Brain Res. 20:9-20.

Matsuo K, Sato K, Ikeshima H, Shimoda K and Takano T (1992) Four synonymous genes encode calmodulin in the teleost fish, medaka (Oryzias latipes): conservation of the multigene one-protein principle. Gene 119:279-281.

Michelhaugh SK, Pimputkar G and Gnegy ME (1998) Alteration in calmodulin mRNA expression and calmodulin content in rat brain after repeated, intermittent amphetamine. Mol. Brain Res. 62:35-42.

Nojima H (1989) Structural organization of multiple rat calmodulin genes. J. Mol. Biol. 208:269-282.

Nojima H, Kishi K and Sokabe H (1987) Multiple calmodulin mRNA species are derived from two distinct genes. Mol. Cell. Biol. 7:1873-1880.

Palfi A and Gulya K (1999) Water deprivation upregulates the three calmodulin genes in exclusively the supraoptic nucleus of the rat brain. Mol. Brain Res. 74:111-116.
Palfi A, Simonka JA, Pataricza M, Tekulics P, Lepran I, Papp G and Gulya K (2001) Postischemic calmodulin gene expression in the rat hippocampus. Life Sciences. 68:2373-81.

Palfi A, Tarcsa M, Varszegi S and Gulya K (2000) Calmodulin gene expression in an immortalized striatal gabaergic cell line. Acta Biologica Hungarica. 51:65-71.

Palfi A, Vizi S and Gulya K (1999) Differential distribution and intracellular targetting of mRNAs corresponding to the three calmodulin genes in rat brain: a quantitative in situ hybridization study. J. Histochem. Cytochem. 47:583-600.

Shimizu Y, Akiyama K, Kodama M, Ishihara T, Hamamura T and Kuroda S (1997) Alteration of calmodulin and its mRNA in rat brain after acute and chronic administration of methamphetamine. Brain Res. 765:247-258.

Shimoda K, Ikeshima H, Matsuo K, Hata J, Maejima K and Takano T (1995) Spatial and temporal regulation of the rat calmodulin gene III directed by a 877 -base promoter and 103-base leader segment in the mature and embryonal central nervous system of transgenic mice. Mol. Brain Res. 31:61-70.

Sola C, Tusell JM and Serratosa J (1997) Differential response of calmodulin genes in the mouse brain after systemic kainate administraion. Neurosci. 78:155-164.

Toutenhoofd SL, and Strehler EE (2000) The calmodulin multigene family as a unique case of genetic redundancy: multiple levels of regulation to provide spatial and temporal control of calmodulin pools? Cell Calcium. 28:83-96.

Weinman J, Gaspera BD, Dautigny A, Dinh DP, Wang J, Nojima $\mathrm{H}$ and Weinman S (1991) Developmental regulation of calmodulin gene expression in rat brain and skeletal muscle. Cell Regul. 2:819-826. 